\title{
The Development of Polypropylene Itaconate (PPIA) for the Film Sensor as Preliminary Study for Meat Distinguisher
}

\author{
Atmanto Heru Wibowo $^{1}$, Silami Dwi Wijayanti ${ }^{1}$, Ryan Crysandi $^{1}$, Ninis Makhnunah ${ }^{1}$, Budi Purnama ${ }^{2}$, Ari Handono \\ Ramelan ${ }^{2}$, Henning Storz ${ }^{3}$ \\ ${ }^{1}$ Chemistry Department, Sebelas Maret University, \\ Jl. Ir. Sutami 36A Kentingan Surakarta Indonesia 57126 \\ ${ }^{2}$ Physic Department, Sebelas Maret University, \\ Jl. Ir. Sutami 36A Kentingan Surakarta Indonesia 57126 \\ Institute of Agricultural Technology, Johann Heinrich von Thuenen Institute, GermanyBundesalle 50, 38116 \\ Braunschweig, Germany \\ *Corresponding author, telp/fax:0858-78677541,email aheruwibowo@staff.uns.ac.id
}

\begin{abstract}
A thin film of PPIA synthesized from polycondensation reaction of itaconic acid (IA) and 1,3propanediol (PDO) with spin coating method has been made. To develop the film property, various glycerols (gly) were added during reaction to form PPIA film with $10 \%, 30 \%, 50 \%$, and $70 \%$ of the total weight of reactans. The molding of thin film was done using spin coater and followed by heating at $150^{\circ}$ for $18 \mathrm{~h}$. The structure change of PPIA before and after film molding was characterized with ATRFTIR. Test of film with and without meat (beef and pork) using LCR meter was aimed to investigate the conductivity response of film for preliminary study of the film use for meat distinguisher. PPIA synthesized were yellowish viscous gel form. The double bond sites on the itaconate group of PPIA before film molding were still remaining as seen on the FTIR spectra. Films molded were yellowish transparent elastic thin film with three dimensional network via double bond sites. Impedance test showed that the film is very potential for meat distinguisher.
\end{abstract}

Keywords :Polypropylene itaconate (PPIA), impedance, thin film, spin coating

\section{Introduction}

Classical method for fat analysis of food production is commonly based on the chromatography method. Gas chromatography (GC) and high performance liquid chromatography (HPLC) are instruments that are mostly used for fat analysis. Flame ionization detector (FID) and conductivity thermal are deployed as detector for the analysis with GC. Ultraviolet beam, fluorescence or mass spectrometry (MS) is in tandem with HPLC. The Polymerase Chain Reaction (PCR) is also able to be used for the analysis by amplification of short sequence DNA and detection using gel electrophoresis ${ }^{1}$

The classical fat analysis is not simple and need more pretreatments such as sample destructions and clean-up process. Rapid analysis of fat in the meat industry without any preliminary treatment is very helpful especially for the inspection of meat-use product in the Islamic countries that are very sensitive with the present of pork in the food. Thus, rapid-analysis sensor with good selectivity, low cost, simple use, portable device is very useful for this purpose in the quality control, exporting feedstock or food processing ${ }^{2}$

Enzyme-based biosensor deployed together with electrochemistry affords the best chance in the food field as enzyme offers biological or chemical conversion with high selectivity and with specific result $3,4,5,6,7$. The biosensor has ability to collect and synchronize biological components such as strain, protein, enzyme, antibody, tissue with electronic signals for detection, signal recording and to transfer signal 
accurately. Due to specific sensing, bio sensor is only to respond only appropriate substance ${ }^{8}$. Biosensor which is used based on the dielectric property of substance is used for water-content sensor in the food ${ }^{9}$, quality analysis of feedstock ${ }^{10}$ and analysis of olive oil in the vegetable $\mathrm{oil}^{11}$. Dielectric property is needed to understand the material behavior related to electromagnetic surrounding in the certain frequency and temperature ${ }^{12}$ and is depend on the frequency, temperature, water content, hardness, composition and the structure of the material ${ }^{13}$. Dielectric constant for food sensing is influenced by unsaturation content of the fat

Itaconic acid is one of diacids group which is very potential to be used as raw material for some uses as it can be reacted with other substances for polymer, plastic, surfactans etc. ${ }^{14}$. As the production of itaconic acid now commercially can be done via high-quantity fermentation, exploration of itaconic-acid based material shall be also intensively done. Some reactions to convert itaconic acids have been done through active groups of diacids or unsaturated sites ${ }^{15,16}$ Polycondensation of IA with various diols has been fewer reported than other organic acids for example succinic acid. The double bonds on the structure differs IA with other organic acids and direct the development of IA as raw material wider ${ }^{17}$. The development of IA for film and coating is a study field was not much reported.

\section{Experimental}

\subsection{Synthesis of PPIA/PPIA-Gly}

PPIA was synthesized by polycondensation reaction in the presence of the catalyst $\mathrm{Ti}(\mathrm{OBu})_{4}$ and optionally pmethoxy phenol in nitrogen and vacuum condition. Three necked flask equipped with magnetic stirrer, nitrogen inlet, a condenser and thermometer is chosen for the condensation reaction. PPIA-Gly was synthesized with the same method with PPIA. The polymerization was done at $170^{\circ} \mathrm{C}$ for $100 \mathrm{~min}$ with nitrogen followed at $150{ }^{\circ} \mathrm{C}$ with vacuum.

\subsection{Film Casting of PPIA/PPIA-Gly}

Gel-viscous PPIA/PPIA-Gly was deposited on the glass plate with $5 \times 5 \mathrm{~cm}$ and followed by coating with 1000 rpm rotational speed for 20 seconds. Film plate was heated at $150{ }^{\circ} \mathrm{C}$ for 18 hours.

\section{Result and Discussions}

\subsection{PPIA}

PPIA polyester synthesized from polycondensation of IA and PDO was viscous dark-yellow gel as seen on figure 1. First step of condensation was with nitrogen gas in which oligomer product was formed. In the condensation stage with vacuum (at $150^{\circ} \mathrm{C}, 10 \mathrm{mBar}$ ), the long chain from the condensation was formed in which water as side product could be maximally pulled out of the main reactor. The molecular weight of the polyester formed was about $5000 \mathrm{~g} /$ mole (based on GPC measurement)

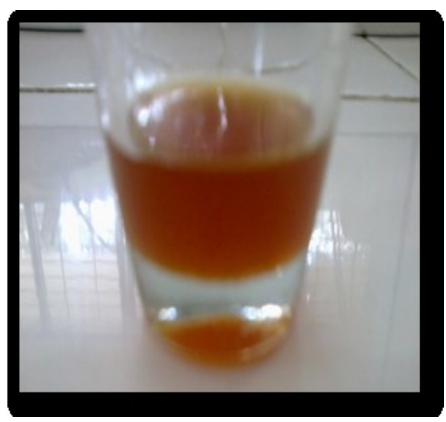

Fig. 1. Dark-yellow gel of PPIA

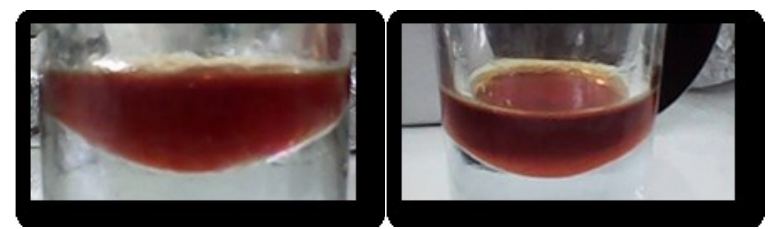

A B

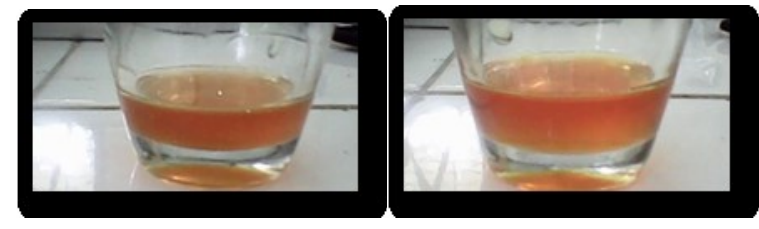

C

D
Fig. 2. Polyester of PPIA-Gly 10\% (A), 30\% (B), 50\% (C), and $70 \%(\mathrm{D})$ 


\subsection{PPIA-Gly}

The addition of glycerol in the synthesis of PPIA changed the color of the polyester in which glycerol content in the PPIA increased, brighter color would be seen. Figure 2 showed that polyester products formed from condensation of IA and PDO with the addition of various glycerol were seen with different color. The three-dimensional networking was formed via the bonding of three-hand hydroxyl group of the glycerol and carboxylic acid if glycerol was added.

\subsection{Film Molding of PPIA-Gly using spin- coating}

The three dimensional networking with the present of glycerol in the polyester film showed brighter color film formed than of without or few of glycerol content in the film. The film with glycerol content affords the three dimensional-networking structure of the polymer. This influences the rigidity increase of the film. Figure 3 showed that polyester-film surface molded by spin coater and after heating at $150^{\circ} \mathrm{C}$ for $18 \mathrm{~h}$ in the oven. Variation of the glycerol content in the film differ the color of the film.

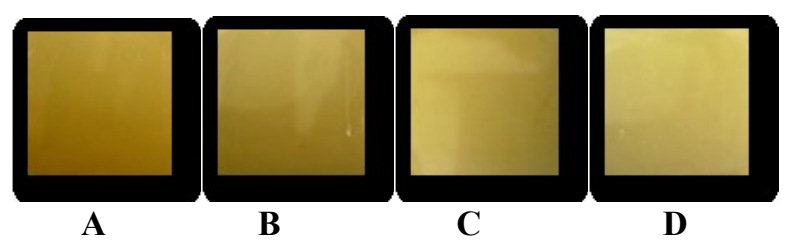

Fig. 3. Thin Film of PPIA-Gly 10\% (A), 30\% (B), 50\% (C), and $70 \%(\mathrm{D})$

Figure 4 showed the structure change of PPIA polyester after additions of various glycerols. The investigation of FTIR showed that the mole increase of the glycerol in the PPIA synthesis reduce the condensation of the hydroxyls group and the carboxylic group due to the glycerol owing three hydroxyl groups caused steric hindrance of the reaction compared to linear-chain diols. It can be seen by the wavelength number on $3500 \mathrm{~cm}^{-1}$. The intensity of the hydroxyl group on the specific wavelength number after addition of glycerol increases smoothly by the increase of the glycerol. The double bond group on the itaconate chain was still remains during the polycondensation reaction that could be seen by the wavelength number at 2900$3000 \mathrm{~cm}^{-1}$. The double bond on the aliphatic chain during the reaction was thermally covered by $\mathrm{p}$ methoxy phenol.

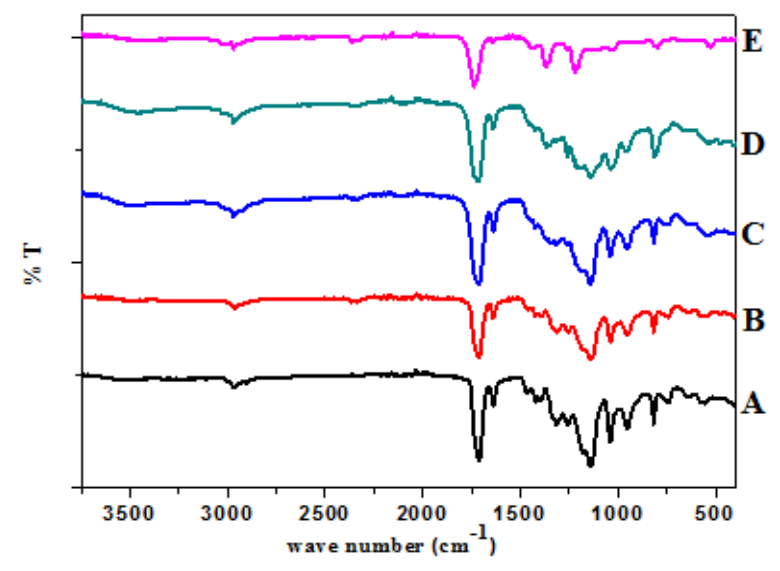

Fig. 4. Infrared spectra of PPIA (A), PPIA-Gly $10 \%$ (b), 30\% (c), $50 \%(\mathrm{D})$, and $70 \%(\mathrm{E})$

Table 1. Infrared spectra of PPIA/PPIA-Gly

\begin{tabular}{|c|c|c|c|c|}
\hline \multirow{2}{*}{ Vibration } & \multicolumn{4}{|c|}{ wave number of PPIA-Gly $\left(\mathrm{cm}^{-1}\right)$} \\
\cline { 2 - 5 } & $10 \%$ & $30 \%$ & $50 \%$ & $70 \%$ \\
\hline $\begin{array}{c}\text { O-H } \\
\text { streching }\end{array}$ & $\begin{array}{c}3487- \\
3454\end{array}$ & $\begin{array}{c}3577- \\
3436\end{array}$ & $\begin{array}{c}3494- \\
3091\end{array}$ & $3488-$ \\
3392 \\
\hline $\begin{array}{c}\text { C-H } \\
\text { streching }\end{array}$ & 2975 & 2977 & 2981 & 2972 \\
\hline $\begin{array}{c}\mathrm{C}=\mathrm{O} \\
\text { streching }\end{array}$ & 1716 & 1730 & 1728 & 1722 \\
\hline $\begin{array}{c}\mathrm{C}=\mathrm{C} \\
\text { streching }\end{array}$ & 1641 & 1681 & 1643 & 1643 \\
\hline $\begin{array}{c}\mathrm{C}-\mathrm{O} \\
\text { stretching }\end{array}$ & 1147 & 1149 & 1149 & 1155 \\
\hline
\end{tabular}

The change of polyester before and after film forming of polyester can be seen at the wave number of $2900-3000 \mathrm{~cm}^{-1}$ and at about $1640 \mathrm{~cm}^{-1}$ as seen on figure 4. The double bond on the itaconate group was broken during the heating to likely single bond. It can be seen also the increase of the intensity of C-C stretching after film forming at wavenumber $2800 \mathrm{~cm}^{-1}$. 


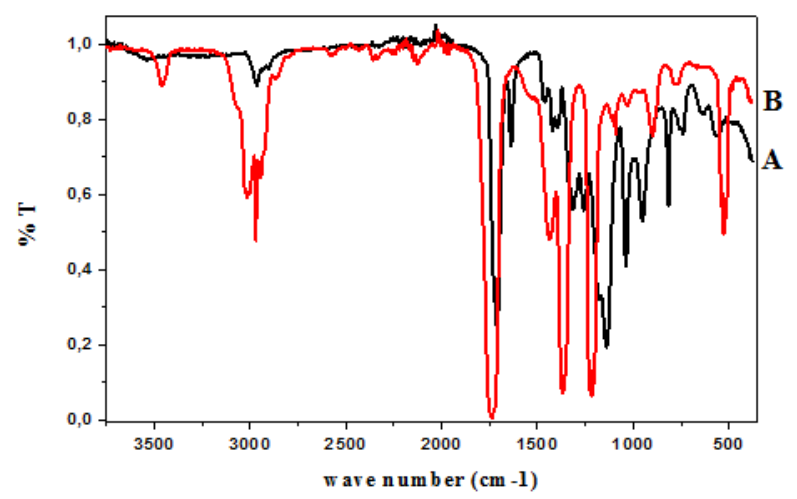

Fig. 5. FTIR Spectra of PPIA before heating (A) and PPIA thin film (B)

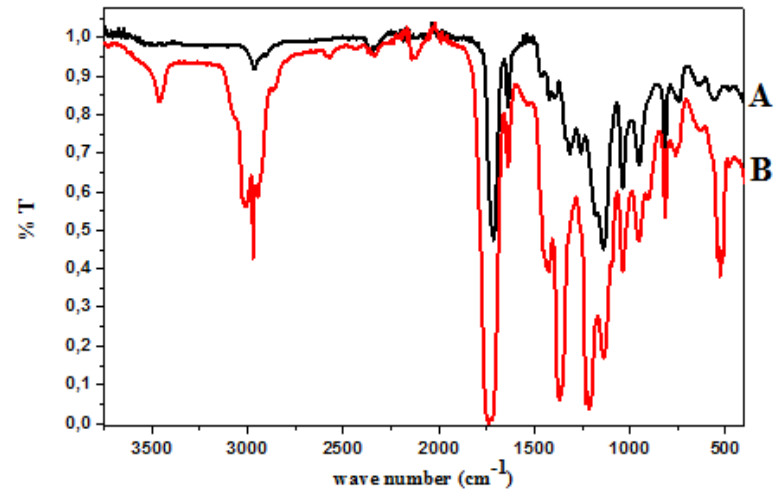

Fig. 6. FTIR Spectra of PPIA-Gly before heating (A) and PPIA-Gly thin film (B)

The change of double bond on the itaconate during heating process occurred before and after heating at $150^{\circ} \mathrm{C}$ process for PPIA and PPIA-Gly as seen on the figure 5 and 6 . This can be seen at wavenumber 3000 $\mathrm{cm}^{-1}$ in which the intensity of $-\mathrm{C}=\mathrm{C}$ - absorption clearly decreased.

Figure 7 showed the FTIR spectra of the various glycerol additions in the PPIA polyester. It was seen that no significant different of the polyester forming with the present of the various glycerols. The difference of the polyester was on the sum of three dimensional networking on the polymer due to present of glycerol. The increase of the glycerol addition increased theoretically the networking on the linear polyester.

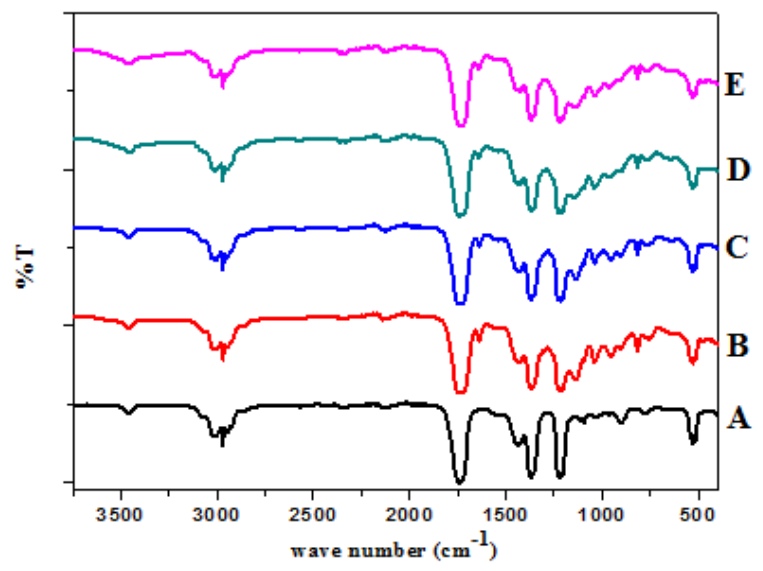

Fig. 7. FTIR spectra film of PPIA (A) and film PPIAGly 10\% (B), 30\% (C), 50\% (D), and 70\% (E)

a. Charakterization of the PPIA-Gly with the LCR meter.

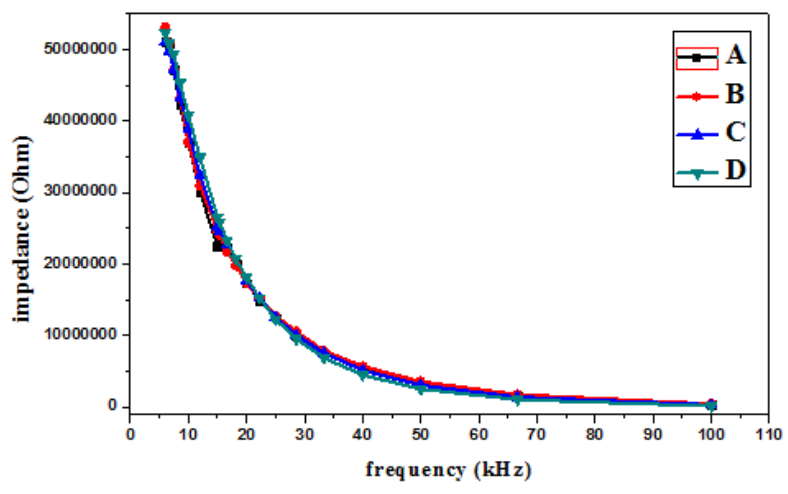

Fig. 8. Impedance profile of thin film PPIA-Gly $10 \%$ (A), $30 \%(B), 50 \%(C)$, and $70 \%(D)$

As seen on the figure 8, during the measurement of the film, a tendency of impedance decrease of all films was showed as frequency of the film increased. Various concentration of glycerol added in the PPIA film influenced no significant differences of impedance among the films whenever frequencies applied. This curve of impedance versus the frequency of the film response is able to be user for the application for the sensor of pork-beef distinguisher as the impedance response would have gave significant different curves. 


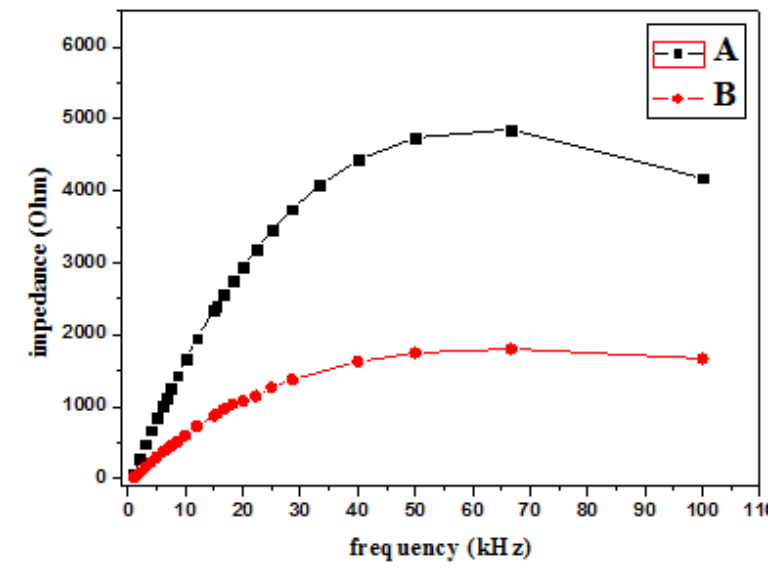

Fig. 9. Impedaance Profile of PPIA-10 \% Gly for beef (A) and pork (B).

Figure 9 showed that the impedance films between with pork and beef showed significant different. It was assumed that this polyester PPIA-10\% Gly film synthesized can be used well after $40 \mathrm{kHZ}$ for the meat distinguisher sensor. This study is still a preliminary study of the forming and use of the polyester synthesized from IA and PDO for the meat sensor applications. However, the study showed a promising result of the PPIA-10\% Gly for meat distinguisher in the application of sensor material in which beef respond higher than pork.

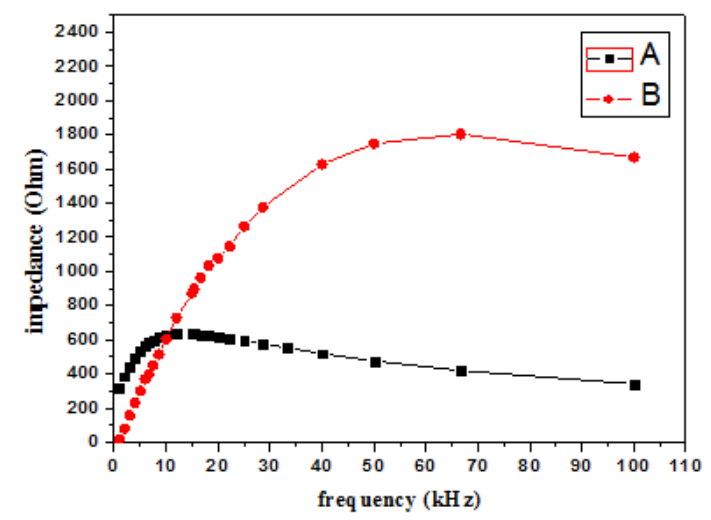

Fig. 10. Profile impedance of pork (A) and PPIA-10\% Gly film with pork (B)

Figure 10 showed impedances of pork and PPIAGly $10 \%$ film with pork probe versus frequency. It was seen from the figure that the film of PPIA-Gly can increase the response of the pork. It was assumed that this polyester of PPIA-10\% Gly film synthesized can be used well to increase the pork response for meat distinguisher in the sensor application

\section{Conclusion}

The various addition of glycerol on the PPIA influenced no significant change on the film structure as glycerol afforded only the mechanical properties of the film that is needed to be further investigation. Film of PPIA with variation of glycerol content affords no significant response toward impedance yielded whenever frequency applied. PPIA-10\% Gly film is able to increase response of pork after $15 \mathrm{kHZ}$ frequency indicating the potential use of this film for meat distinguisher.

\section{References}

1. Lazcka O, Del Campo FJ, Muñoz FX. Pathogen detection: A perspective of traditional methods and

2. biosensors. Biosens and Bioelectron 2007; 22(7):1205- 1217

3. Maria Teresa Giardi, Giuseppina Rea and Bruno Berra 2010. Bio- Farms for Nutraceuticals: Functional Food and Safety Control by Biosensors. Landes Bioscience and Springer Science+Business Media

4. Zhang S, Wang N, Yu H, Niu Y, and Sun C. Covalent attachment of glucose oxidase to an $\mathrm{Au}$ electrode modified with gold nanoparticles for use as glucose biosensor. Bioelectrochemistry 2005;67(1):15- 22.

5. Azevedo AM, Prazeres DM, Cabral JM, and Fonseca LP. Ethanol biosensors based on alcohol oxidase. Biosens and Bioelectron 2005; 21(2):235-247.

6. Liu Y, Qu X, Guo H, Liu B, and Dong S. Facile preparation of amperometric laccase biosensor with multifunction based on the matrix of carbon nanotubeschitosan composite. Biosensor and Bioelectron 2006 21:2195- 2201

7. Prieto- Simón B, Fàbregas E. New redox mediator- ${ }^{-}$modified polysulfone composite films for the development of dehydrogenase-based biosensors. Biosens and Bioelectron 2006; 22(1):131 - 137.

8. Mita DG, Attanasio A, Arduini F, Diano N, Grano V, Bencivenga U, Rossi S, Amine A, and Moscone D Enzymatic determination of BPA by means of tyrosinase immobilized on different carbon carriers. Biosens and Bioelectron 2007; 23(1):60- 65 .

9. Arshak, Khalil., Velusamy, Vijayalakshmi ., Korostynska, Olga., Oliwa-Stasiak, Kamila., and Adley, Catherine. 2009. Conducting Polymers and Their Applications to Biosensors: Emphasizing on Foodborne 
Pathogen Detection. IEEE SENSORS JOURNAL, VOL. 9, NO. 12. Hal 1942-1951

10. Toyoda, K. 2003. The Utilization of Electric Properties. In: Sumio, K. (Ed). The Handbook Of Non-Destructive Detection. Science forum, Tokyo: 108-126 (Chapter 8).

11. Venkatesh, M. S. \& G. S. V. Raghavan. 2004. An overview of microwave processing and dielectric properties of agri-food materials. Biosyst. Eng. 88: 1-11.

12. Lizhi H., K. Toyoda, \& I. Ihara.2010. Discrimination of olive oil adulterated with vegetable oils using dielectric spectroscopy. J. Food Eng. 96: 167-171.

13. Sosa-Morales, M. E., L. Valerio-Junco, A. López-Malo, \& H. S. García. 2010. Review dielectric properties of foods: Reported data in the 21 st century and their potential applications. LWT-Food Sci. Technol. 43:11691179.

14. Castro-Giráldez, M., P. J. Fito, F. Toldrá, \& P. Fito.2010. Physical Sensors For Quality Control During Processing. In: F. Toldrá (Ed). Handbook of Meat Processing. WileyBlackwell, Oxford. Pp. 443-456

15. Ouyang, Q., Cheng, L., Wang, H., and Li, K., 2008, Mechanism and kinetics of the stabilization reactions of itaconic acid-modified polyacrylonitrile, Polymer degradation and stability, 93, 1415-1421

16. Ferraboschi, P., Casati, S., Grisenti, P., and Santaniello, E., 1994, Selective enzymatic transformations of itaconic acid derivatives: An access to potentially useful building blocks, The International Journal for the Rapid Publication of Critical, 50,3251-3258

17. Willke, Th., and Vorlop, K.D., 2001, Biotechnological Production of Itaconic Acid, Application Microbiology Biotechnology, 56:289-295

18. Lanthong, P., Nuisin, R., and Kiatkamjornwong, S., 2006, Graft copolymerization, characterization, and degradation of cassava starch-g-acrylamide/itaconic acid superabsorbents, Journal of carbohydrate polymers, 66, 229-245. 